\title{
Effects of rabeprazole on bone metabolic disorders in a gastrectomized rat model
}

\author{
YUKI YAMASAKI, TAKASHI FUJIMURA, KATSUNOBU OYAMA, YUKI HIGASHI, ATSUSHI HIROSE, \\ TOMOYA TSUKADA, KOICHI OKAMOTO, JUN KINOSHITA, KEISHI NAKAMURA, TOMOHARU MIYASHITA, \\ HIDEHIRO TAJIMA, HIROYUKI TAKAMURA, ITASU NINOMIYA, SACHIO FUSHIDA and TETSUO OHTA
}

Department of Gastroenterological Surgery, Kanazawa University Hospital, Kanazawa, Ishikawa 920-8641, Japan

Received February 12,2016; Accepted April 27, 2016

DOI: 10.3892/br.2016.689

\begin{abstract}
Proton pump inhibitors (PPIs) are frequently prescribed to patients with gastroesophageal reflux disease; however, the number of bone fractures reportedly increased in these patients. Although PPIs have been shown to inhibit the bone resorption by osteoclasts, the effect of PPIs on skeletal metabolism remains controversial. The aim of the present study was to determine the effect of the PPI rabeprazole on skeletal metabolism using gastrectomized rats. Male Wistar rats were divided into four groups: i) Sham-surgery $(n=15)$; ii) total gastrectomy (TG) control $(\mathrm{n}=20)$; iii) TG plus rabeprazole ( $\mathrm{n}=20)$; and iv) TG plus the bisphosphonate minodronic acid $(n=20)$. Twenty-two weeks after TG, the rats were sacrificed, and bone mineral density (BMD), bone strength and markers for bone metabolism were measured. Compared with the control group $(50.0 \pm 8.1 \%)$, the TG-induced decrease in BMD was significantly ameliorated in the rabeprazole group $(56.5 \pm 7.5 \%)$ and the minodronic acid group $(59.0 \pm 6.0 \%)$. However, rabeprazole did not improve bone strength. In conclusion, rabeprazole does not appear to exacerbate bone metabolic disorders in gastrectomized rats, but rather ameliorates the TG-induced BMD decrease.
\end{abstract}

\section{Introduction}

Osteoporosis is a well-known disease and caused 9 million osteoporotic fractures worldwide in the year 2000 (1). Osteoporotic fractures occurring at the spine and the forearm are associated with significant morbidity, but the most serious consequences arise in patients with hip fractures. The mortality rate is $20 \%$ in the first year following hip fracture (2). Among those who survive this period, 1 in 5

Correspondence to: Dr Katsunobu Oyama, Department of Gastroenterological Surgery, Kanazawa University Hospital, 13-1 Takaramachi, Kanazawa, Ishikawa 920-8641, Japan

E-mail: oya-ma@staff.kanazawa-u.ac.jp

Key words: gastrectomy, bone metabolic disorder, bone mineral density, proton pump inhibitor, raberprazole requires nursing home care (3). Thus, osteoporosis is associated with not only morbidity, but also decline in the quality of life. Osteoporosis is classified as primary osteoporosis induced by menopause or aging and secondary osteoporosis. Well-known causes of secondary osteoporosis include, endocrine disorders, such as Cushing's syndrome, hypogonadism, hyperthyroidism, hyperparathyroidism and diabetes mellitus (4). Gastrointestinal diseases, such as inflammatory bowel disease (5), rheumatoid arthritis (6) and myeloma bone disease (7), also induce osteoporosis. In addition, the incidence of osteoporosis following gastrectomy has become a clinical issue. Although numerous studies have examined bone metabolic disorders following gastrectomy since it was first reported by Sarasin (8), the pathophysiology and the treatment of these disorders have not been fully elucidated. Based on experimental results using rat models, general nutritional deficiencies (9), calcium malabsorption (10), vitamin D deficiency (11), loss of gastric acid (12) and secondary hyperparathyroidism (13) have been suggested as possible causes of bone metabolic disorder following gastrectomy. However, fully understanding the morbidity and developing clinical therapies for skeletal disorders is critical for improving patient quality of life.

Recent epidemiological studies have shown that long-term therapy with proton pump inhibitors (PPIs) significantly increases the risk of osteoporosis and pathological hip fracture in patients with gastroesophageal reflux disease (14). It is thought that PPIs reduce the production and secretion of hydrochloric acid in stomach, increase the $\mathrm{pH}$ in the stomach and inhibit absorption of insoluble calcium in the small intestine, thus leading to malabsorption of calcium phosphate and bone metabolism disorder $(15,16)$. PPIs also reportedly inhibit bone resorption by osteoclasts $(17,18)$. However, the irreversible PPI mediated by the PPIs requires a specific $\mathrm{pH}$ environment. PPIs are all prodrugs that require two sequential protonation steps for activation (19). In the first step, a pyridine radical is activated, and in the second step, a benzimidazole radical is activated. The first step is required for accumulation of the PPI in the intracellular secretory canaliculus, and the second step is necessary for binding of the PPI with the proton pump. The $\mathrm{pKa}$ in the second step does not significantly differ $(<1)$ among the various PPIs (such as rabeprazole, lansoprazole and omeprazole), whereas the pKa for the first step with 
rabeprazole (4.53) is higher compared to that for lansoprazole (3.83) and omeprazole (4.06) (20). This suggests that rabeprazole can efficiently combine with the proton pump to produce an immediate effect (21). For the two sequential protonation steps, the proton pump inhibitory action of the PPIs is extremely site-specific. In addition to the secretory canaliculi of the gastric parietal cells, the osteoclastic resorption vacuole may be the only other place in which proton pump inhibition by PPIs is known to occur. Clinical studies have supported the theory that the short-term use of a PPI reduces bone resorption markers $(18,22)$. There are conflicting data regarding the effect of PPIs on bone metabolism, with little known concerning the effects of PPIs on osteoclasts and bone resorption.

Therefore, the present study analyzed the effect of PPIs on bone metabolism following total gastrectomy (TG) in a rat model of osteoporosis. Using the rat TG model, poor calcium absorption that is observed during gastric anacidity was reproduced and the confounding antisecretory activity of the PPI was excluded to determine the specific effect of a PPI on osteoclasts.

\section{Materials and methods}

Ethical approval. All the procedures performed in the studies involving animals adhered to the Standard Guidelines for Animal Experiments at Kanazawa University (Kanazawa, Ishikawa, Japan; date of issue: May 18, 2012; registration number: AP-122484).

Animals. In total, 75 male Wistar rats (Charles River Laboratories Japan, Inc., Kanagawa, Japan) that were 12 weeks of age were used for the experiments. The rats were housed three to a cage, and were maintained at a room temperature of $22 \pm 3^{\circ} \mathrm{C}$ and humidity of $55 \pm 5 \%$ with a 12 -h light-dark cycle. The rats were provided a standard solid chow, CRF-1 (Charles River Laboratories Japan, Inc.) and tap water. The animal welfare committee of Kanazawa University approved the experiments.

Drugs. The effects of the PPI rabeprazole on bone metabolism were compared with those of minodronic acid, a bisphosphonate clinically administered in the treatment of patients with osteoporosis. Minodronic acid was obtained from Astellas Pharma, Inc. (Tokyo, Japan), and rabeprazple was obtained from Eisai Co., Ltd. (Tokyo, Japan).

Experimental design. The rats were randomly divided into the following four groups: i) Sham-surgery $(n=15)$; ii) TG control $(\mathrm{n}=20)$; iii) TG plus rabeprazole $(30 \mathrm{mg} / \mathrm{kg})$ administered three times per week $(n=20)$; iv) TG plus minodronic acid (0.04 mg/kg/day) $(\mathrm{n}=20)$. Beginning 4 weeks after surgery, rabeprazole was administered subcutaneously three times per week for 18 weeks to the rats in the TG plus rabeprazole group, and minodronic acid was administered subcutaneously daily for 18 weeks to the rats in the TG plus minodronic acid group. The rationale for the dose of rabeprazole used was based on prior studies, which showed that a subcutaneous dose of rabeprazole at $30 \mathrm{mg} / \mathrm{kg}$ to rats reduced acid secretion by $100 \%$ within $4 \mathrm{~h}$, with the return of acid secretion to normal levels at 3 days $(23,24)$.
Surgery. After $24 \mathrm{~h}$ of fasting, the rats were anesthetized with intraperitoneal injections of medetomidine, midazolam and butorphanol. TG using the reconstructed Roux-en-Y method was performed through an upper middle incision. The duodenal stump was closed with sutures. The jejunum was amputated $\sim 6 \mathrm{~cm}$ distal to the ligament of Treitz. The esophageal stump was anastomosed to the anal side of amputated jejunum in an end-to-side manner. The jejunojejunostomy was performed in a side-to-side manner. Intestinal anastomosis was performed with interrupted full-thickness stitches using 7-0 monofilament suture. The rats had free access to water and food beginning $24 \mathrm{~h}$ after surgery.

Autopsy. Blood samples were obtained and the animals were sacrificed by exsanguination under isoflurane anesthesia 22 weeks after the surgery. The serum samples were immediately separated from the blood by centrifugation at $1,000 \mathrm{xg}$ for $10 \mathrm{~min}$, and the serum was frozen and stored at $-80^{\circ} \mathrm{C}$ until used for analysis. Femurs were isolated for evaluation, and the soft tissue was removed. Femurs were wrapped in saline-soaked gauze and stored at $-80^{\circ} \mathrm{C}$ until used for analysis.

Bone morphometry and density. The right femur was fixed in $10 \%$ neutral buffered formalin, degreased in $100 \%$ ethanol, re-fixed in cyanuric chloride (Wako Pure Chemical Industries, Osaka, Japan) and decalcified with formic acid. Thin sections of the right femur were made with a sliding microtome (Leica SM-2000R; Leica Biosystems, Nussloch, Germany). The sections were stained with hematoxylin and eosin (H\&E) stain. The amount and width of each trabecular bone, correlated with bone strength, was traced distal to epiphyseal line using a bio-imaging navigator (Biorevo BZ-9000; Keyence, Osaka, Japan). The range of calcified bone was extracted. The area of the calcified bone in the traced range was calculated using analytical software (Hybrid Cell Count Software; Keyence).

Bone strength. The bending strength of the left femur was measured with a three-point bending test using a mechanical testing machine (AG-X; Shimadzu, Kyoto, Japan). The specimen was placed horizontally in the loading section of the machine. The center of the diaphysis was pressed with $50 \mathrm{kgf}$; the distance from the support point was $15 \mathrm{~mm}$. The breaking strength in Newtons $(\mathrm{N})$ was used as a measure of bone strength.

Serum biochemistry. Biochemical measurements, including serum calcium, phosphorus, total protein and albumin were measured with an auto-analyzer (Hitachi 7180; Hitachi High-Technologies, Tokyo, Japan).

Bone metabolism. Serum tartrate-resistant acid phosphatase $5 \mathrm{~b}$ (TRACP-5b), a bone resorption marker, and bone-specific alkaline phosphatase (BAP), a bone formation marker, were used as biochemical markers of turnover and, measured using an enzyme immunoassay (Rat TRACP-5b ELISA; Cusabio Biotech Co., Ltd., Wuhan, China).

Statistical analysis. Continuous variables are expressed as mean \pm standard deviation. Comparisons between groups were 


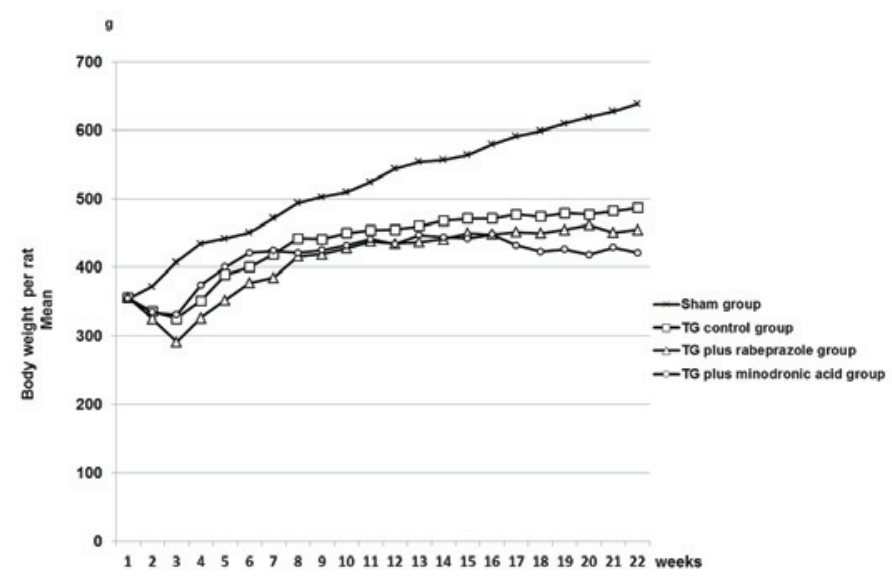

Figure 1. Changes in body weight of the rats 22 weeks after surgery in each experimental group. The body weights of the rats in the sham group increased gradually throughout the study period, whereas those in the TG groups remained nearly constant after week 8 . No significant differences were observed in body weights between the three TG groups. TG, total gastrectomy.

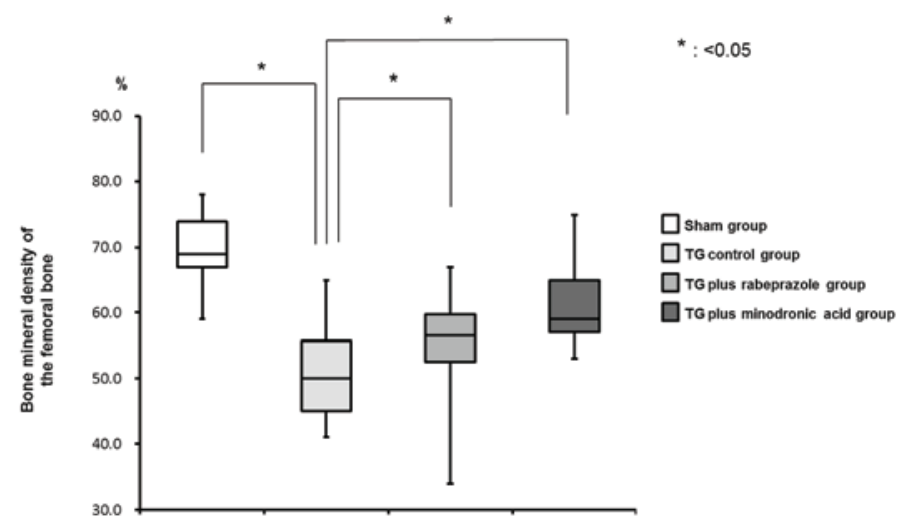

Figure 2. Bone mineral density of the femoral bone. Twenty-two weeks after surgery, the rate of the calcified bone area in the traced area in the TG control group $(50.0 \pm 8.1 \%)$ was lower than that in the sham group (69.0 $\pm 5.6 \%)$. The rates in the TG plus rabeprazole (56.5 $\pm 7.5 \%)$ and TG plus minodronic acid $(59.0 \pm 6.0 \%)$ groups were significantly higher than that in the TG control group $\left({ }^{*} \mathrm{P}<0.05\right)$. TG, total gastrectomy.

made using the Mann-Whitney $\mathrm{U}$ test. $\mathrm{P}<0.05$ was considered to indicate a statistically significant difference.

\section{Results}

Final sample numbers. Subsequent to being assigned to the experimental groups, 1 rat died in the TG plus rabeprazole group, and 3 rats died in the TG plus minodronic acid group. All 4 rats succumbed to ileus; none from drug toxicity. No rats died in the sham-surgery or TG control groups. Of the 75 assigned animals, 71 rats survived 22 weeks post-surgery and were included in the study (15 in the sham group, 20 in the TG control group, 19 in the TG plus rabeprazole group, and 17 in the TG plus minodronic acid group).

Body weights. Changes in the body weights of the rats in each experimental group are shown in Fig. 1. Body weights of the rats in the TG group were reduced in weeks 1-2. The body weights of the rats in the sham group increased gradually throughout the study period, whereas those in the TG groups remained nearly constant after week 8 . No significant differences in the body weights were observed among the three TG groups.
Bone mineral density (BMD) of the femur. Twenty-two weeks after TG, the rate of the calcified bone area in the traced are in the TG control group $(50.0 \pm 8.1 \%)$ was lower than that in the sham group $(69.0 \pm 5.6 \%)$ (Fig. 2). The rates in the TG plus rabeprazole $(56.5 \pm 7.5 \%)$ and TG plus minodronic acid $(59.0 \pm 6.0 \%)$ groups were significantly higher than that in the TG control group $(\mathrm{P}<0.05)$. These results indicated that rabeprazole inhibited the TG-induced BMD decrease with an effect comparable to that of minodronic acid (Fig. 2).

Bone strength. Femoral bending strength was markedly decreased in the TG control group $(152.34 \pm 24.01 \mathrm{~N} \bullet \mathrm{m})$ compared with that in the sham group $(251.99 \pm 23.14 \mathrm{~N} \bullet \mathrm{m})$. This effect was significantly ameliorated and also counteracted with minodronic acid treatment $(190.50 \pm 26.95 \mathrm{~N} \bullet \mathrm{m})$, but not by the rabeprazole treatment $(151.67 \pm 22.41 \mathrm{~N} \bullet \mathrm{m})$ (Fig. 3).

Serum biochemistry. Compared with that in the sham group, the serum calcium levels were reduced in rats with TG, while the serum phosphorus levels remained unchanged by TG or by the administration of either minodronic acid or rabeprazole. Minodronic acid significantly decreased the serum calcium level compared with the level in the TG control 


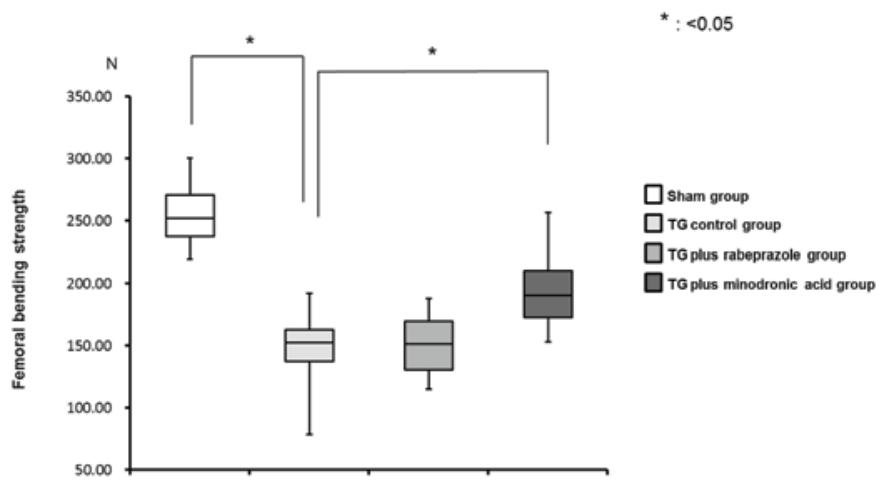

Figure 3. Femoral bending strength in the different groups. Femoral bending strength was markedly decreased in the TG control group $(152.34 \pm 24.01 \mathrm{~N} \bullet \mathrm{m})$ compared with that in the sham group $(251.99 \pm 23.14 \mathrm{~N} \bullet \mathrm{m}$; " $\mathrm{P}<0.05)$. Femoral bending strength in the TG plus minodronic acid group $(190.50 \pm 26.95 \mathrm{~N} \bullet \mathrm{m})$ was higher than that in the TG control group $($ ( $\mathrm{P}<0.05)$. Whereas, femoral bending strength in the TG plus rabeprazole group $(151.67 \pm 22.41 \mathrm{~N} \bullet \mathrm{m})$ is equal with that in the TG control group. TG, total gastrectomy.

A

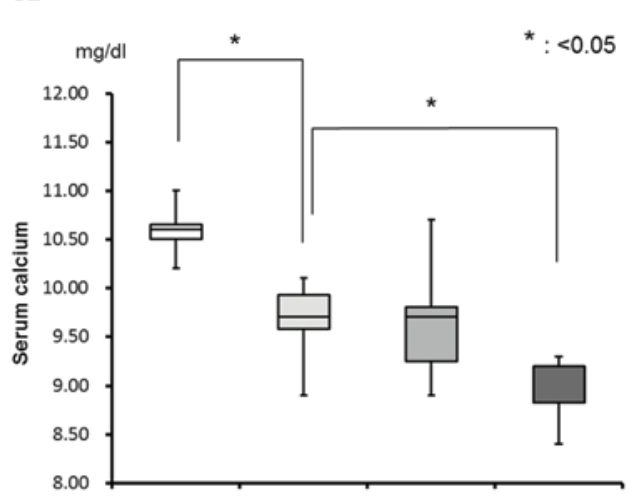

B
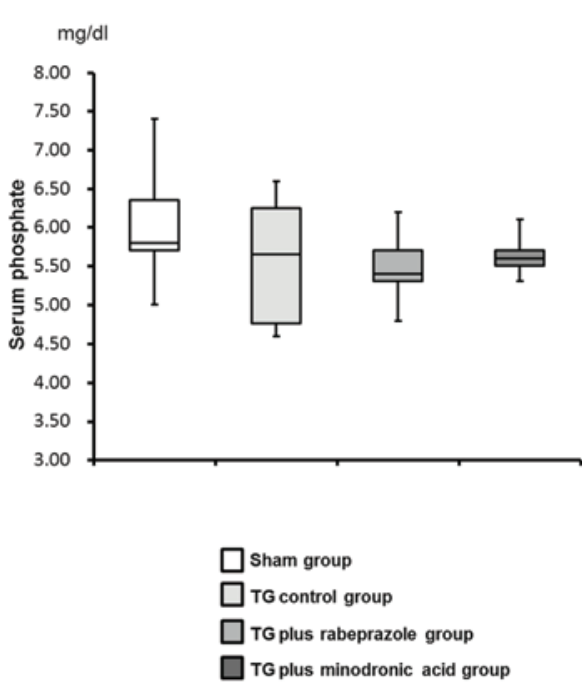

Figure 4. (A) Serum calcium and (B) phosphorus levels in the different groups. Compared with that in the sham group, the serum calcium levels were reduced in rats with TG $(" \mathrm{P}<0.05)$. Minodronic acid significantly decreased the serum calcium level compared with the level in the TG control group $(" \mathrm{P}<0.05)$. By contrast, rabeprazole did not affect serum calcium levels. The serum phosphorus levels remained unchanged by TG or by the administration of either minodronic acid or rabeprazole. TG, total gastrectomy.

group $(\mathrm{P}<0.05)$. By contrast, rabeprazole did not affect serum calcium levels (Fig. 4).

Bone metabolism. No significant differences in serum TRACP-5b levels were observed between the four groups (Fig. 5A). The serum BAP level was reduced in rats with TG compared with that in the sham group. The administration of minodronic acid or rabeprazole did not ameliorate this serum BAP decrease (Fig. 5B).

Bone morphology. The morphology of the femoral metaphysis stained with H\&E stain was observed microscopically (Fig. 6). The trabecular sponge-like network in the metaphysis (arrowhead in Fig. 6) and trabecular separation (asterisks in Fig. 6) were compared across the four groups. The width (bidirectional arrow in Fig. 6) in the TG control group was thinner than that in the sham group. By contrast, the width was wider in the rabeprazole and minodronic acid-treated groups compared to the TG control group.

\section{Discussion}

The present study demonstrated the effects of rabeprazole on bone metabolic disorders in gastrectomized rats. Minodronic acid almost completely blocked the TG-induced decreases in bone density and bone strength. Rabeprazole also inhibited the TG-induced decrease in bone density.

PPIs reduce gastric acid secretion, and are thus widely used in conditions such as gastroesophageal reflux, Zollinger-Ellison syndrome, dyspepsia and peptic ulcer disease (25). For years, PPIs were considered safe, without any major complications during long-term use (26). However, Yang et al (27) conducted a nested case-control study using the General Practice Research Database and examined 
A

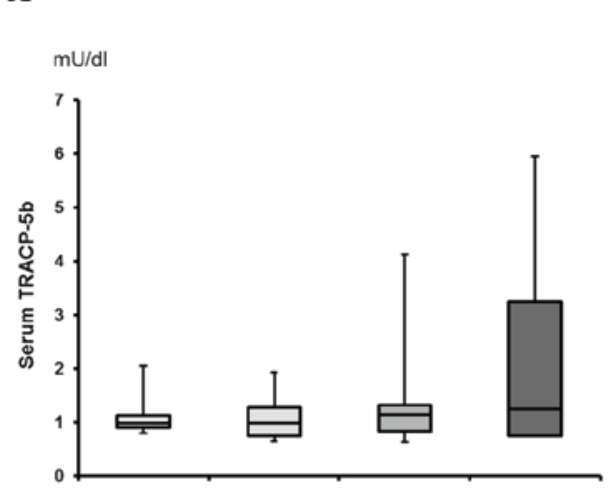

B

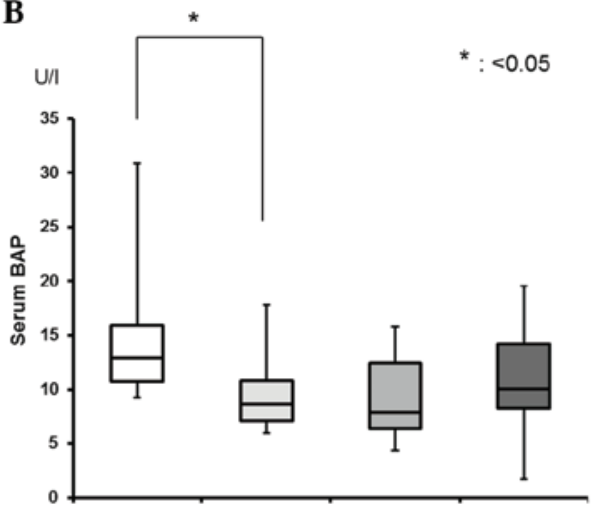

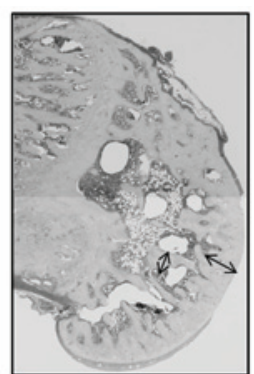
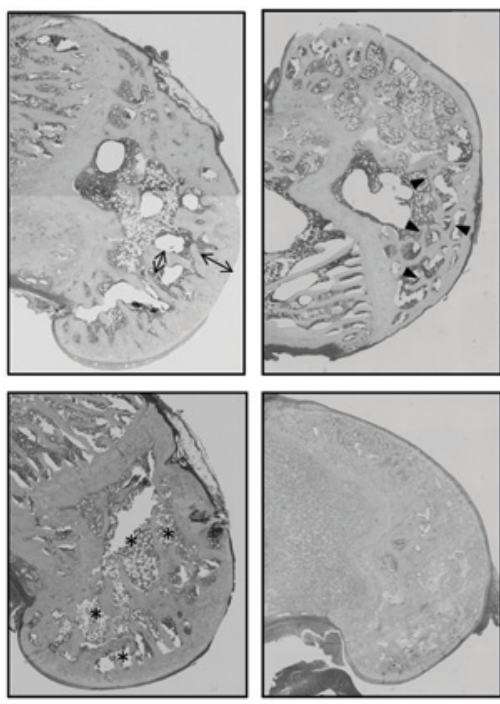

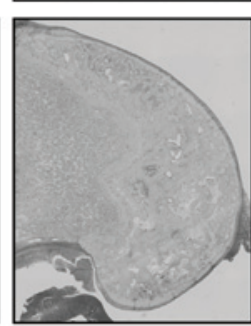

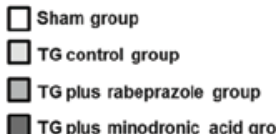

$\square$ TG plus minodronic acid group

Figure 5. (A) Serum TRACP-5b and (B) BAP levels in the different groups. No significant differences were observed in the serum TRACP-5b levels between the four groups. The serum BAP level was reduced in rats with TG compared with that in the sham group ("P<0.05). The administration of minodronic acid or rabeprazole did not ameliorate this serum BAP decrease. TRACP-5b, tartrate-resistant acid phosphatase 5b; BAP, bone-specific alkaline phosphatase; TG, total gastrectomy.

Figure 6. Micrographs of the femur, focusing on the metaphysis of the distal end (H\&E stain). The morphology of the femoral metaphysis stained with H\&E stain was observed microscopically. The trabecular sponge-like network in the metaphysis (arrowhead) and trabecular separation (asterisks) were compared across the four groups. The width (bidirectional arrow) in the TG control group was thinner than that in the sham group. By contrast, the width was wider in both the rabeprazole and minodronic acid treated groups than in the TG control group. TG, total gastrectomy; H\&E, hematoxylin and eosin.

the risk of hip fractures associated with PPI use. The study reported that the risk of hip fracture was markedly increased among long-term users of high-dose PPI therapy. PPIs were recently identified as an independent risk factor for osteoporotic fracture (14,27-31). PPIs reportedly increase the risk of osteoporotic fracture by causing hypochlorhydria, reducing intestinal calcium absorption and subsequently inducing a negative calcium balance $(26,30)$. However, existing studies provide conflicting information regarding the direct effects of PPIs on calcium absorption. Hansen et al (32) administered omeprazole $(40 \mathrm{mg} / \mathrm{day})$ to menopausal women for 30 days and reported that 30 days of continuous PPI therapy did not alter calcium absorption, suggesting that PPI-associated hypochlorhydria does not reduce calcium absorption.

However, several in vitro studies have reported that PPIs inhibit the vacuolar-ATPase of osteoclasts and reduce their activity $(33,34)$. Sheraly et al $(35)$ examined the potential of PPIs to prevent osteoclast-mediated resorption of calcium phosphate cements in vivo. The study reported that the PPIs (pantoprazole and high-dose omeprazole) produced a delay in osteoclast resorption. Ohta et al (22) administered rabeprazole ( $10 \mathrm{mg}$ /day for 8 weeks) to 22 non-osteoporotic patients presenting with upper gastrointestinal symptoms and investigated the effect of rabeprazole on bone metabolism. 
They reported that rabeprazole did not affect BAP, but significantly decreased type I collagen cross-linked N-telopeptides. However, in humans and rat models, the effect of PPIs on bone metabolism appears complicated as PPIs have contradictory effects: Inhibition of calcium absorption by gastric acid suppression versus inhibition of osteoclasts. The association between PPI-associated hypochlorhydria and the decrease in calcium absorption remains controversial.

In the present study, the TG rat model was used to exclude the PPI-induced effect on gastric acid secretion and examine the PPI-induced inhibition of bone resorption mediated by osteoclasts in skeletal metabolism. The results demonstrated that rabeprazole ameliorated the reduction in bone density induced by TG at the distal end of the femur, indicating that rabeprazole may control osteoclastic bone resorption, similar to bisphosphonate.

However, rabeprazole did not ameliorate the reduction in bone strength at the femoral diaphysis. This may be due to the improvement in bone density by rabeprazole, which was milder than that of the bisphosphonate. The difference between cancellous bone and cortical bone may also be one of the causes. Iwamoto et al (36) examined the influence of TG on cortical and cancellous bones in rats. The study measured the bone mineral content and density and the mechanical strength of the femoral distal metaphysis and diaphysis. The TG-induced osteopenia and deterioration in bone strength were more severe at skeletal sites rich in cancellous bone (distal metaphysis) compared with those rich in cortical bone (diaphysis). The present study measured bone density at the femoral distal metaphysis, rich in cancellous bone. However, bone strength was measured at the femoral diaphysis, rich in cortical bone and thus less affected by gastrectomy or medication than cancellous bone. This may be one reason that administration of rabeprazole did not appear to affect bone strength in the present study.

The serum BAP level in the TG groups was significantly lower than that in the sham group, whereas the serum TRACP-5b levels in all groups were similar. This result indicates that the bone metabolic disorder induced by TG is more dependent on suppressing the bone formation compared to on increasing bone resorption. Although in the group with TG plus the bisphosphonate the serum TRACP-5b level appeared lower than those in the other TG groups, the individual variability was large and this difference was not statistically significant. It is plausible that feedback occurred and altered the level of this marker, however, this change could not be captured as the present study examined only chronic associations. TRACP-5b is not considered a reflection of bone metabolism in this particular model.

As aforementioned, osteoporosis following gastrectomy has become a clinical issue. In patients receiving proximal gastrectomy or pylorus preserving gastrectomy, which preserves gastric acid secretion, reflux of gastric acid could be another cause of esophagitis. PPIs are typically effective in these patients $(37,38)$. Certain epidemiological studies suggested that PPIs induce skeletal metabolism disorders. However, due to the effect of PPIs on osteoclasts, the administration of PPI may improve TG-induced bone metabolic disorders. The present study used the TG model to reproduce the poor calcium absorption that occurs during gastric anacidity. As the effect of calcium malabsorption due to rabeprazole-induced gastric acid suppression could be excluded, the specific effects of rabeprazole on osteoclasts could be examined. Rabeprazole inhibited the TG-induced bone density decrease, suggesting that the administration of a PPI is at least not an exacerbating factor in bone metabolic disorders.

\section{Acknowledgements}

The authors thank Dr Seiji Naganuma, Department of Pathology, Kochi University, for the expert advice on the pathological bone density measurement method.

\section{References}

1. Johnell O and Kanis JA: An estimate of the worldwide prevalence and disability associated with osteoporotic fractures. Osteoporos Int 17: 1726-1733, 2006

2. Cumming RG, Nevitt MC and Cummings SR: Epidemiology of hip fractures. Epidemiol Rev 19: 244-257, 1997.

3. Leibson CL, Tosteson AN, Gabriel SE, Ransom JE and Melton LJ III: Mortality, disability, and nursing home use for persons with and without hip fracture: A population-based study. J Am Geriatr Soc 50: 1644-1650, 2002.

4. Hofbauer LC, Hamann C and Ebeling PR: Approach to the patient with secondary osteoporosis. Eur J Endocrinol 162: 1009-1020, 2010

5. Bernstein CN, Leslie WD and Leboff MS: AGA technical review on osteoporosis in gastrointestinal diseases. Gastroenterology 124: 795-841, 2003.

6. van Staa TP, Geusens P, Bijlsma JW, Leufkens HG and Cooper C: Clinical assessment of the long-term risk of fracture in patients with rheumatoid arthritis. Arthritis Rheum 54: 3104-3112, 2006.

7. Melton LJ III, Kyle RA, Achenbach SJ, Oberg AL and Rajkumar SV: Fracture risk with multiple myeloma: A population-based study. J Bone Miner Res 20: 487-493, 2005.

8. Sarasin C: Osteomalacie und hypochrome anaemie nach magenresektion. Gastroenterologia 66: 182-197, 1941.

9. Klinge B, Lehto-Axtelius D, Akerman M and Håkanson R: Structure of calvaria after gastrectomy. An experimental study in the rat. Scand J Gastroenterol 30: 952-957, 1995.

10. Lehto-Axtelius D, Surve VV, Johnell O and Håkanson R: Effects of calcium deficiency and calcium supplementation on gastrectomy-induced osteopenia in the young male rat. Scand J Gastroenterol 37: 299-306, 2002.

11. Axelson J, Persson P, Gagnemo-Persson R and Håkanson R: Importance of the stomach in maintaining calcium homoeostasis in the rat. Gut 32: 1298-1302, 1991.

12. Persson P, Gagnemo-Persson R, Chen D, Axelson J, Nylander AG, Johnell $\mathrm{O}$ and Häkanson R: Gastrectomy causes bone loss in the rat: Is lack of gastric acid responsible? Scand J Gastroenterol 28: 301-306, 1993.

13. Mühlbauer RC, Schenk RK, Chen D, Lehto-Axtelius D and Hâkanson R: Morphometric analysis of gastrectomy-evoked osteopenia. Calcif Tissue Int 62: 323-326, 1998.

14. Targownik LE, Lix LM, Metge CJ, Prior HJ, Leung S and Leslie WD: Use of proton pump inhibitors and risk of osteoporosis-related fractures. CMAJ 179: 319-326, 2008.

15. Chonan O, Takahashi R, Yasui H and Watanuki M: Effect of L-lactic acid on calcium absorption in rats fed omeprazole. J Nutr Sci Vitaminol (Tokyo) 44: 473-481, 1998.

16. O'Connell MB, Madden DM, Murray AM, Heaney RP and Kerzner LJ: Effects of proton pump inhibitors on calcium carbonate absorption in women: A randomized crossover trial. Am J Med 118: 778-781, 2005.

17. Tuukkanen $J$ and Väänänen HK: Omeprazole, a specific inhibitor of $\mathrm{H}+-\mathrm{K}+-\mathrm{ATPase}$, inhibits bone resorption in vitro. Calcif Tissue Int 38: 123-125, 1986.

18. Mizunashi K, Furukawa Y, Katano K and Abe K: Effect of omeprazole, an inhibitor of $\mathrm{H}+, \mathrm{K}(+)$-ATPase, on bone resorption in humans. Calcif Tissue Int 53: 21-25, 1993.

19. Shin JM, Cho YM and Sachs G: Chemistry of covalent inhibition of the gastric $(\mathrm{H}+, \mathrm{K}+)$-ATPase by proton pump inhibitors. J Am Chem Soc 126: 7800-7811, 2004. 
20. Sachs G, Shin JM, Vagin O, Lambrecht N, Yakubov I and Munson K: The gastric H,K ATPase as a drug target: Past, present, and future. J Clin Gastroenterol 41 (Suppl 2): S226-S242, 2007.

21. Saitoh T, Fukushima Y, Otsuka H, Hirakawa J, Mori H, Asano T, Ishikawa T, Katsube T, Ogawa $\mathrm{K}$ and Ohkawa S: Effects of rabeprazole, lansoprazole and omeprazole on intragastric $\mathrm{pH}$ in CYP2C19 extensive metabolizers. Aliment Pharmacol Ther 16 1811-1817, 2002.

22. Ohta T, Hashimoto T, Murai $\mathrm{H}$ and Kimura $\mathrm{H}$ : Influence of proton pump inhibitor on bone metabolism marker. J N Rem Clin 57: 1341-1345, 2008.

23. Kawai T, Ikeda H, Harada Y and Saitou T: Changes in the rat stomach after long-term administration of proton pump inhibitors (AG-1749 and E-3810). Nihon Rinsho 50: 188-193, 1992 (In Japanese).

24. Miyashita T, Shah FA, Marti GP, Wang J, Bonde P, Gibson MK, Ohta T,Montgomery EA,Duncan Mand Harmon JW: Rabeprazole impedes the development of reflux-induced esophageal cancer in a surgical rat model. Dig Dis Sci 56: 1309-1314, 2011.

25. Savarino V, Di Mario F and Scarpignato C: Proton pump inhibitors in GORD An overview of their pharmacology, efficacy and safety. Pharmacol Res 59: 135-153, 2009.

26. Jacobson BC, Ferris TG, Shea TL, Mahlis EM, Lee TH and Wang TC: Who is using chronic acid suppression therapy and why? Am J Gastroenterol 98: 51-58, 2003.

27. Yang YX, Lewis JD, Epstein S and Metz DC: Long-term proton pump inhibitor therapy and risk of hip fracture. JAMA 296: 2947-2953, 2006.

28. Vestergaard P, Rejnmark L and Mosekilde L: Proton pump inhibitors, histamine $\mathrm{H} 2$ receptor antagonists, and other antacid medications and the risk of fracture. Calcif Tissue Int 79: 76-83, 2006.

29. de Vries F, Cooper AL, Cockle SM, van Staa TP and Cooper C: Fracture risk in patients receiving acid-suppressant medication alone and in combination with bisphosphonates. Osteoporos Int 20: 1989-1998, 2009.
30. Yu EW, Blackwell T, Ensrud KE, Hillier TA, Lane NE, Orwoll E and Bauer DC: Acid-suppressive medications and risk of bone loss and fracture in older adults. Calcif Tissue Int 83: 251-259, 2008.

31. Roux C, Briot K, Gossec L, Kolta S, Blenk T, Felsenberg D, Reid DM, Eastell R and Glüer CC: Increase in vertebral fracture risk in postmenopausal women using omeprazole. Calcif Tissue Int 84: 13-19, 2009.

32. Hansen KE, Jones AN, Lindstrom MJ, Davis LA, Ziegler TE, Penniston KL, Alvig AL and Shafer MM: Do proton pump inhibitors decrease calcium absorption? J Bone Miner Res 25: 2786-2795, 2010.

33. Karsdal MA, Henriksen K, Sørensen MG, Gram J, Schaller S, Dziegiel MH, Heegaard AM, Christophersen P, Martin TJ, Christiansen C, et al: Acidification of the osteoclastic resorption compartment provides insight into the coupling of bone formation to bone resorption. Am J Pathol 166: 467-476, 2005.

34. Niikura K, Takeshita N and Takano M: A vacuolar ATPase inhibitor, FR167356, prevents bone resorption in ovariectomized rats with high potency and specificity: Potential for clinical application. J Bone Miner Res 20: 1579-1588, 2005.

35. Sheraly AR, Lickorish D, Sarraf F and Davies JE: Use of gastrointestinal proton pump inhibitors to regulate osteoclast-mediated resorption of calcium phosphate cements in vivo. Curr Drug Deliv 6: 192-198, 2009.

36. Iwamoto J, Sato Y and Matsumoto H: Influence of gastrectomy on cortical and cancellous bones in rats. Gastroenterol Res Pract 2013: 381616, 2013.

37. Someya S, Shibata C, Tanaka N, Kudoh K, Naitoh T, Miura K and Unno M: Duodenal switch for intractable reflux gastroesophagitis after proximal gastrectomy. Tohoku J Exp Med 230: 129-132, 2013.

38. Imada T, Rino Y, Takahashi M, Suzuki M, Tanaka J, Shiozawa M, Kabara K, Hatori S, Ito H, Yamamoto Y, et al: Postoperative functional evaluation of pylorus-preserving gastrectomy for early gastric cancer compared with conventional distal gastrectomy. Surgery 123: 165-170, 1998. 